\title{
Pituitary Adenomas: Presentations and Outcomes in a South Asian Country
}

\author{
Muhammad Shahzad Shamim, Muhammad Ehsan Bari, Faraz Khursheed, \\ Rashid Jooma, Syed Ather Enam
}

\begin{abstract}
Objective: The purpose of this retrospective review of all operated cases of pituitary adenomas in the last decade, is to define the demographic patterns and characteristics of such tumors and to assess surgical outcomes with regards to safety and efficacy of trans-sphenoidal tumor removal in our institution. Methods: Surgically treated pituitary adenomas presenting from 1995 till 2005 were reviewed for different variables. Results were expressed as mean, standard deviation and median for continuous and number with percentage for categorical data. Chi square test was applied to measure differences and significance was taken at $p$ value $<0.05$. Results: One hundred and twenty-five patients were operated for pituitary adenoma. Sixty-three percent were male and mean age was 37 years. Sixty percent of the patients presented with headache and/or visual symptoms. Twelve percent presented with pituitary apoplexy and $28 \%$ presented with symptoms due to pituitary hyperfunction. Fifty-five percent of patients had functioning and $44 \%$ had nonfunctioning adenomas. Mean pre operative tumor diameter from 86 pre op MRI scans was $26.76 \mathrm{~mm}$ (3-78 mm). Eighty-four percent of patients underwent trans-sphenoidal tumor resection and three percent had craniotomy. Mean size of post op residual tumor as calculated from 76 available post operative scans was $5.3 \mathrm{~mm}$ (range 0-31 mm). 17.6\% of the patients required hormone replacement beyond three months and $10 \%$ were re-operated. Overall mortality was $1.6 \%$. Conclusion: In Pakistan, patients are more likely to present either with apoplexy or with a giant pituitary adenoma than patients reported from developed countries. Overall, our results have been satisfactory and comparable with the literature.
\end{abstract}

RÉSUMÉ: Adénomes pituitaires : mode de présentation et évolution dans un pays du Sud de l'Asie. Objectif : Le but de cette revue rétrospective de tous les cas d'adénomes pituitaires opérés au cours de la dernière décennie était de définir le profil démographique et les caractéristiques de ces tumeurs et d'évaluer les résultats chirurgicaux en termes de sécurité et d'efficacité de l'ablation trans-sphénoïdale de la tumeur dans notre institution. Méthodes : Nous avons révisé les observations de patients qui ont subi une chirurgie pour adénome pituitaire entre 1995 et 2005. La moyenne, la déviation standard et la médiane ont été calculées pour les variables continues et le pourcentage pour les variables discrètes. Le test du chi-carré a été utilisé pour l'analyse des données et la valeur de p a été fixée à $<0,05$. Résultats : Cent vingt-cinq patients ont subi une chirurgie pour un adénome pituitaire. L'âge moyen était de 37 ans et $63 \%$ étaient des hommes. Soixante pour cent des patients ont consulté initialement pour de la céphalée et/ou des symptômes visuels, $12 \%$ pour apoplexie pituitaire et $28 \%$ pour des symptômes d'hyperpituitarisme. Chez 55\% des patients l'adénome était fonctionnel et chez $44 \%$ l'adénome ne l'était pas. Le diamètre moyen de la tumeur avant la chirurgie, évalué au moyen de 86 IRM préopératoires, était de $26,76 \mathrm{~mm}$ (3 à $78 \mathrm{~mm}$ ). Quatre-vingt-quatre pour cent des patients ont subi une résection trans-sphénoïdale de la tumeur et $3 \%$ ont subi une craniotomie. La taille moyenne de la tumeur résiduelle en postopératoire, calculée au moyen de 76 scans effectués après la chirurgie, était de 5,3 mm (0 à $31 \mathrm{~mm}$ ). Un remplacement hormonal s'est avéré nécessaire chez 17,6\% des patients au-delà de trois mois et on a dû réintervenir chez $10 \%$. La mortalité globale a été de 1,6\%. Conclusion : Au Pakistan, les patients consultent plus souvent pour une apoplexie pituitaire ou un adénome géant que dans les pays développés. Dans l'ensemble, nos résultats ont été satisfaisants et ils sont comparables à ceux rapportés dans la littérature.

Can. J. Neurol. Sci. 2008; 35: 198-203

Pituitary adenomas represent 15 to $19 \%$ of all surgically resected primary brain tumors. ${ }^{1,2}$ In the United States, the estimated annual incidence is 8.2 to 14.7 cases per 100,000 people, making pituitary adenoma the third most common primary intracranial tumor after glioma and meningioma. ${ }^{2}$ Unselected autopsy studies show that 20 to $27 \%$ of the general population harbor subclinical pituitary adenomas, so called 'incidentaloma'. ${ }^{2-5}$ Clinically occult pituitary adenoma can be picked up in $10 \%$ or more of routine MRI scans. ${ }^{6,7}$
Pituitary adenomas occur in all ages but the highest incidence is between the third and sixth decade, with functioning tumors

From the Department of Neurosurgery, Aga Khan University Hospital, Karachi, Pakistan.

Received August 20, 2007. Final Revisions Submitted January 9, 2008. Reprint requests to: Muhammad Ehsan Bari, Department of Neurosurgery, Aga Khan University Hospital, Stadium Road, P.O. Box 3500. Karachi, Pakistan. 


\section{Table 1: Age Distribution (125 cases)}

\begin{tabular}{lcc}
\hline Age (years) & Number & Percentage \\
$0-20$ & 26 & 20.8 \\
$21-30$ & 18 & 14.4 \\
$31-40$ & 27 & 21.6 \\
$41-50$ & 31 & 24.8 \\
$51-60$ & 16 & 12.8 \\
$>60$ & 07 & 5.6 \\
\hline
\end{tabular}

more common in younger age groups. The incidence of nonfunctioning adenomas increase with increasing age. ${ }^{5,8}$ As many as $70 \%$ of all pituitary adenomas are endocrinologically active i.e functional, accordingly pituitary hyperfunction may be the most common presentation of these tumors. ${ }^{9}$ About $1-2 \%$ of all pituitary adenomas present as pituitary apoplexy but subclinical hemorrhage and/or hemorrhagic necrosis is evident in $10 \%$ of all pituitary surgical specimens without an antecedent history of an apoplectic event. ${ }^{1,10-12}$ The imaging classification system proposed by Hardy divides pituitary adenomas into micro $(<10$ mm diameter) and macroadenomas( $>10 \mathrm{~mm}$ diameter), with five grades depending upon the sellar appearance. ${ }^{11}$ The transsphenoidal approach is the most commonly used, minimally traumatic route for pituitary surgeries ${ }^{13,14}$ and is among the safest procedures in neurosurgical practice. ${ }^{15}$ Operative mortality and major morbidity rates are $0.5 \%$ to $1 \%$ and $2.2 \%$ to $3.4 \%$ respectively in different series. ${ }^{4,16-18}$ Lesser morbidity has been reported in $4-5 \%$ of patients. ${ }^{16,17}$

The purpose of this retrospective review of all operated cases of pituitary adenomas in the past decade in our institution was to define the demographic patterns and characteristics of these tumors and assess surgical outcome with regard to the safety and efficacy of trans-sphenoidal tumor resection.

\section{Materials ANd Methods}

A retrospective review of the medical records of 128 patients with the diagnosis of pituitary adenoma who underwent surgical resection as their primary treatment at the Aga Khan University Hospital, Karachi, Pakistan between 1995 to 2005. The files were retrieved using the ICD-9 Clinical Modifications code for pituitary adenoma, pituitary tumor and trans-sphenoidal hypophysectomy. Three patients who had final histopathological diagnosis other than pituitary adenomas were excluded from the study. The data was recorded on a standardized proforma and reviewed for variables including patients' demographics, clinical presentation, biochemical and radiological data, duration of procedure, length of stay, complications of surgery and clinical, biochemical and radiological follow-ups.

All patients had MRI scans before and after surgery, although only $86(69 \%)$ of the preoperative and $76(61 \%)$ of the postoperative scans were available in the hospital radiological records room for comparison at the time of the study. For those patients whose scans were not available for review, information regarding tumor diameter was taken from the resident or consultant pre-operative assessment note. This pre-operative information was considered reliable enough to classify the tumor

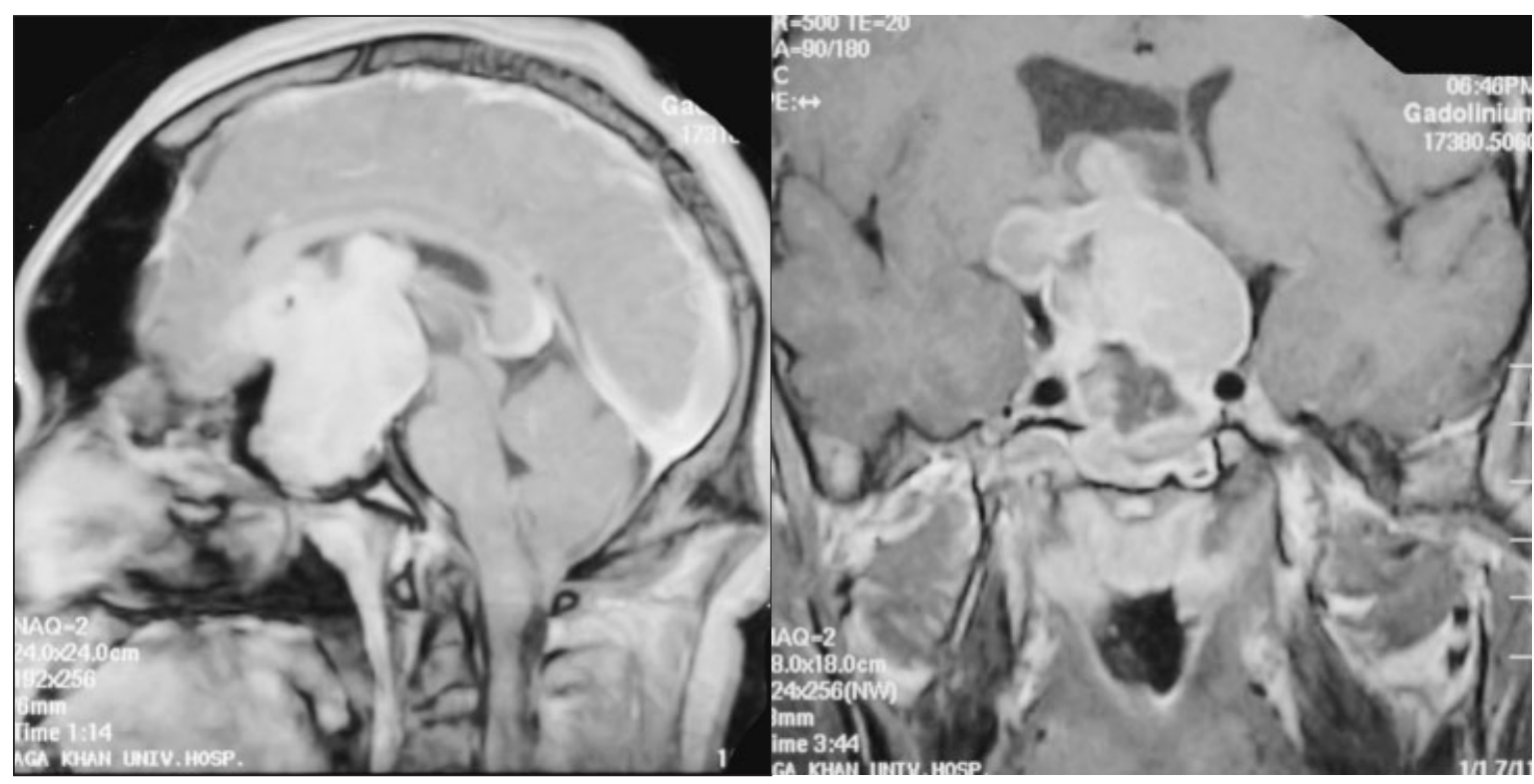

Figure 1,2: Coronal and sagittal views of a giant pituitary adenoma with extensive suprasellar extension 
as a micro or macroadenoma, but comparison of pre- and postoperative tumor size was only done for patients whose scans were available for review. Tumors were classified as macro $(>10$ $\mathrm{mm})$ and microadenomas $(<10 \mathrm{~mm})$ according to their diameters on MRI scans. All patients, except 15 with pituitary apoplexy, underwent complete pre-operative hormonal investigation. Postoperative assessment of hormonal function was done in all 125 patients. Tumors were also classified into functioning and nonfunctioning types according to the patient's hormonal status. All intra-operative and post operative complications were recorded. Temporary diabetes insipidus (lasting $<72$ hours) requiring none or a single dose of intravenous or intranasal Desmopressin was not considered a reportable complication, though diabetes insipidus lasting longer than 72 hours was included. Similarly mild, self-limiting cerebrospinal fluid (CSF) rhinorrhea or temporary hormone replacement after surgery (lasting less than the hospital stay) were not considered adverse effects.

Data was analyzed using Statistical Package for Social Sciences SPSS software and results were expressed as mean $+/$ standard deviation and median with range for all continuous variables and number with percentage for categorical data.

\section{RESULTS}

During the ten year period, a total of 125 patients were operated for sellar masses with the final histopathological diagnosis of pituitary adenoma. Out of these, $79(63.2 \%)$ were male and $46(36.2 \%)$ were female. The mean age of patients at the time of the diagnosis was $37.10(+/-15.7)$ years (Range 1- 76 years). The mean age of male patients was 39.2 years $(+/-16.8)$ and females was 33.5 years $(+/-12.5)$ with the majority of patients $(61$ of $125,48.8 \%)$ in their $3 \mathrm{rd}$ and 4 th decades of life. A relatively high frequency $(26$ of $125,20.8 \%$ ) was noted in the 0-20 year age group.

Headache or visual disturbance or both occurred in $75(60 \%)$ patients including $15(12 \%)$ with pituitary apoplexy (<10 days duration of symptoms). The mean duration of symptoms, excluding those who presented with apoplexy, was 18.08 months (Range 1 month-18 years).

Of 110 patients, who had their preoperative hormone levels assessed, 61 (55.45\%) had functioning and 49 (44.55\%) had nonfunctioning adenomas. Of the 67 males tested, 34 (50.7\% of 67) had functioning and $33(49.2 \%)$ non-functioning adenomas. Amongst females who had pre-op endocrine testing, $27(62.7 \%$ of 43 ) had functioning and $16(37.2 \%)$ non-functioning tumors. Of these 110 patients, $59(47.2 \%)$ had macroadenomas, 44 of these $59(74.5 \%)$ were non-functional and $15(25.4 \%)$ functional. In the group of $51(40.8 \%)$ with microadenomas, $46(90.1 \%)$ were functional and only $5(9.9 \%)$ non-functional ( $p$ value $0.091)$. Raised growth hormone levels were found in $31(50.8 \%)$, prolactin in 20 patients $(32.7 \%)$, cortisol in 18 patients $(29.5 \%)$ and thyroid in 2 patients $(3.2 \%)$ of the 61 patients with functional tumor. Twenty one $(34.4 \%)$ had elevated levels of more than one hormone.

Further analysis of macro and micro adenomas also revealed interesting findings. Of the 59 macroadenomas, there were 42 male and 17 female patients, an almost 2.5:1 male female ratio. In the group of 51 microadenomas, there were 25 male and 26 female patients, a near 1:1 male female ratio ( $p$ value 0.018 ). Remaining 15 of the total 125 patients (12\%) had pituitary
Table 2: Preoperative Tumor Size* (86 cases)

\begin{tabular}{lccc}
\hline Size $(\mathbf{m m})$ & No. of cases & Percentage & Cumulative \% \\
$1-10$ & 18 & 21.0 & 21.0 \\
$11-20$ & 17 & 19.8 & 40.8 \\
$21-30$ & 19 & 22.1 & 62.9 \\
$31-40$ & 14 & 16.3 & 79.0 \\
$41-50$ & 14 & 16.3 & 95.3 \\
$>50$ & 04 & 4.7 & 100 \\
\hline
\end{tabular}

* refers to largest diameter of tumor expressed in millimeters

apoplexy and are excluded from all preceding calculations. Twelve of 15 patients $(80 \%)$ presenting with pituitary apoplexy were male ( $\mathrm{p}$ value 0.02 ). The mean diameter of tumor on 86 preoperative MRI scans reviewed was $26.76 \mathrm{~mm}$ (+/-15.7, Range 3$78 \mathrm{~mm}$ ). Eighteen (20.9\%) tumors were more than $40 \mathrm{~mm}$ diameter (giant adenomas) while 18 were characterized as microadenomas $(<10 \mathrm{~mm})$ (Table 2$)$.

In 105 cases the surgical approach used was trans-nasal transsphenoidal, in 16 cases a trans-labial trans-sphenoidal approach was used, and craniotomy was done in four patients. The mean operative time was $122.75 \mathrm{~min}$ (+/- 60.4, Range 45-500 $\mathrm{min})$. Mean length of stay in the hospital was 8.78 days (+/- 8.1, Range: 2-73 days). Final histopathology revealed pituitary adenoma in $110(88 \%)$ patients and pituitary apoplexy in 15 (12\%) patients. The mean clinical follow-up was 17.34 months (+/- 20.0 months, Range 1-96 months). Radiological follow-up of 8.79 months (+/- 11.97 months, Range 0-48 months) was available in 76 of the patients. Mean maximum diameter of residual adenomas in these seventy six patients was $5.30 \mathrm{~mm} \mathrm{(+/-}$

Table 3: Post Operative Residual Tumor+ (76 cases)

\begin{tabular}{lccc}
\hline $\begin{array}{l}\text { Residential } \\
\text { Tumor }\end{array}$ & No. of Cases & Percentage & Cumulative \% \\
$0-5$ & 48 & 63.0 & 63.0 \\
$6-25$ & 06 & 7.9 & 70.9 \\
$26-50$ & 12 & 15.8 & 86.7 \\
$51-75$ & 08 & 10.5 & 97.2 \\
$76-100$ & 02 & 2.7 & 100 \\
\hline
\end{tabular}

+ expressed in percentage of preoperative tumor size 
Table 4: Graph Distribution of Micro and Macroadenomas in Relation to Gender and Functional Status

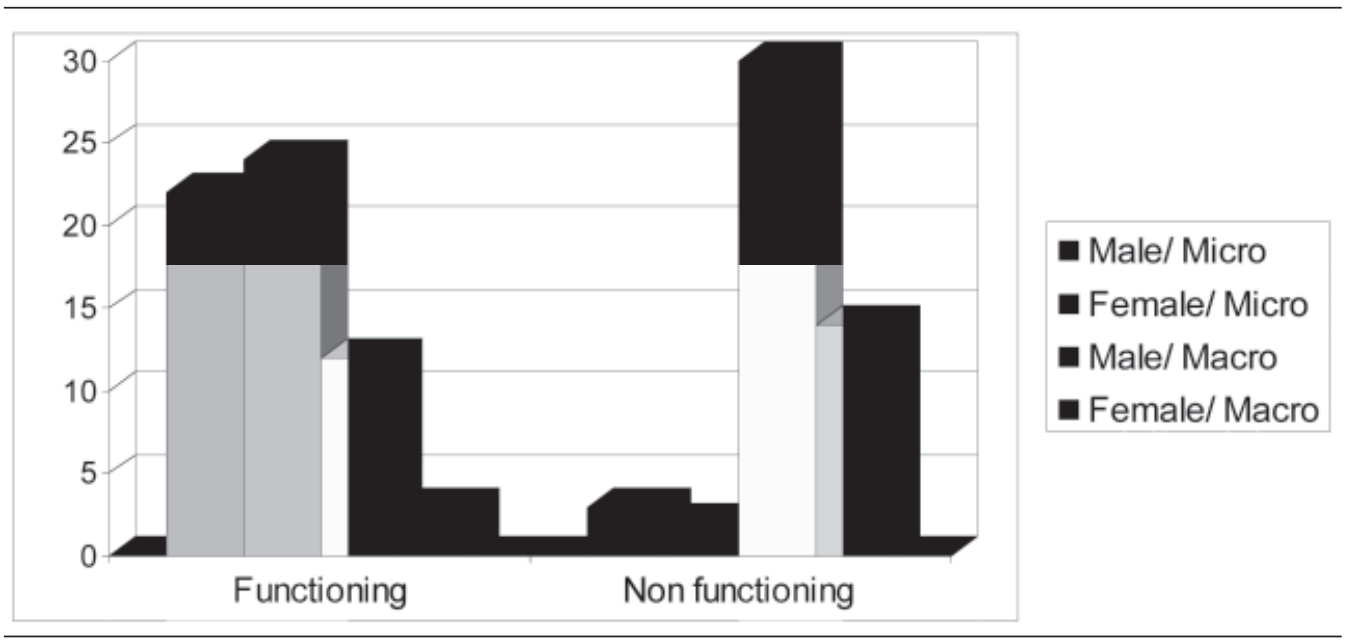

$9.1 \mathrm{~mm}$, Range 0-31 mm) with complete resection (described as less than $5 \%$ residual tumor) in 51 of the cases. Overall, more than $50 \%$ resection was achieved in $66(86.7 \%)$ of these 76 patients (Table 3 ). Post operative hormonal supplementation was required in $60(46.9 \%)$ of the patients with only $22(17.6 \%)$ requiring hormone supplementation beyond three months. Post operative radiotherapy was given to $21(16.4 \%)$ of the patients. Thirteen $(10.3 \%)$ patients underwent re-operations for residual tumor.

The only peri-operative mortality $(0.8 \%)$ occurred due to excessive blood loss during a craniotomy for macroadenoma in a nine-month-old child. Another patient had a fatal pulmonary embolism, making the overall mortality rate $1.6 \%$. Major complications included CSF rhinorrhea in 5 (3.9\%), meningitis in $4(3.2 \%)$, stroke in $1(0.8 \%)$ and a non-fatal pulmonary embolism in $1(0.8 \%)$ patient. Transient diabetes insipidus occurred in $14(11.2 \%)$ and was permanent in 4 (3.2\%). Other hospital acquired infections like chest and urinary tract infections occurred in $6(4.8 \%)$ of the patients.

\section{DisCUSSION}

In contrast to the report of Mindermann and Wilson, males were more common $(n=79,63.2 \%)$ than females $(n=46,36.8 \%)$ in our series. ${ }^{19}$ Studies of other medical problems in Pakistan have shown a predominance of male patients, possibly because they are more likely than females to seek medical care. ${ }^{6,20}$ Like most other series, the mean age of female patients (33.5 years) presenting with pituitary adenomas is less than that of males (39.2 years). ${ }^{19,21}$

In our series, there was a relatively increased frequency $(\mathrm{n}=$ $26,20.8 \%$ ) of patients less than 20 years of age. Pituitary adenomas are reported to represent only $2-5 \%$ of all primary brain tumors in children as compared to $15-19 \%$ in adults..$^{1,5,19,22-24}$ The increased frequency of relatively younger patients in our series may be explained on the basis of lack of pediatric neurosurgical expertise in our country and our institution's growing reputation as the leading neurosurgical centre in Pakistan. Only a handful of centers in our country have the facilities for minimally invasive neurosurgical procedures such as the trans-sphenoidal route for pituitary surgery. Also, only a few centers have advanced ophthalmological, endocrinological, pediatric specialties and supporting laboratory and radiology facilities, which are all essential in the work-up and diagnosis of such patients. We can therefore speculate that younger patients tend to be referred to us more than older patients for further work up and management.

The most common presentation of pituitary adenomas globally is believed to be due to endocrinological abnormalities. ${ }^{15}$ However in this series, $60 \%(n=75)$ of the patients presented with symptoms of headache, visual disturbances or both. This is perhaps due to unavailability of laboratories equipped for endocrine work-up or lack of trained medical staff to diagnose functioning adenomas on clinical grounds. Another important finding was the strikingly high number of patients $(\mathrm{n}=15,12 \%)$ who presented with apoplexy. Internationally reported data suggest that only $1-2 \%$ of patients with pituitary adenoma present with apoplexy. $2,10,17,25$ It is difficult to speculate whether such high numbers represent a difference in tumor biology in our patient population, or unique social and economic factors which prevent patients from seeking medical attention for symptoms which do not appear immediately threatening as compared to sudden loss of vision. Interestingly, $80 \%$ of patients presenting with apoplexy were male, an observation which was statistically significant ( $p$ value 0.02 ). Since there is no scientific evidence to date for male preponderance in apoplexy, this observation is indicative of under reporting of such events in female patients which is a cause for concern. 
Another statistically significant difference between male and female patients was noted when comparing micro and macroadenomas. Male patients were more likely to present with a macro adenoma (male to female ratio 2.5:1) when compared with female patients who were more likely to present with micro adenomas ( $p$ value 0.018). An observation of relatively less significance is the greater frequency of functional adenomas in females ( $p$ value 0.091 ). Although in our center, the frequency of functionally active tumors $(\mathrm{n}=61,55.45 \%)$ was higher than functionally inactive adenomas $(n=49,44.55 \%)$, the literature reports much greater difference, with the frequency of endocrine disturbances as high as $70 \% .{ }^{15}$ The difference may be explained by the lack of diagnostic facilities as we have already mentioned, and also based on the smaller number of female patients in our study, as they are generally more likely to present with endocrinopathies. Only six of 46 female patients presented with menstrual irregularities. In contrast to the published literature, prolactinomas in our study were not the most commonly encountered functioning adenomas. ${ }^{15}$ The majority of macroadenomas in our series were nonfunctioning, while most of the microadenomas were functionally active, a pattern reported in the literature.

Eighteen $(20.9 \%)$ of our patients had giant pituitary adenomas although the reported frequency is not more than $6 \% .^{12}$ We found more macroadenomas $(n=59,47.2 \%)$ than microadenomas $(n=51,40.8 \%)$. Similar statistics $(13.7 \%)$ have recently been reported in a series from Mumbai. ${ }^{9}$ There are several possible explanations for the difference in our series. The tumors may be biologically different, perhaps on a genetic basis, but a more likely explanation rests with our social and economic factors and our healthcare system. Poor people may ignore symptoms such as headache and fatigue which do not interfere with daily work but seek medical attention for symptoms such as progressive or loss of vision, or persistent headaches. The low literacy rate and huge popularity of various forms of alternative medicine may result in patients being provided with symptomatic care only, without a thorough clinical examination and appropriate investigation. Unavailability of specialized healthcare in remote areas and absence of a proper referral system in areas where healthcare is otherwise available also contributes to delay in care. Hence patients in our population were more likely to present with pituitary apoplexy and giant pituitary tumors than patients in more developed countries. The demographic characteristics of patients in our series were so different from the reported literature, that we are forced to speculate that the reason may not be tumor behavior, but rather it is human behavior. We are missing out on the majority of patients with pituitary adenomas; those patients who do get to the neurosurgeons do so due to their overwhelming symptoms.

The trans-sphenoidal approach was the major route for tumor removal in our institution. In $63 \%(n=48)$ of the 76 patients whose post operative MRI scans were available, the tumor resection was complete, defined as less than $25 \%$ residual tumor. More than $50 \%$ resection of tumor and remission of symptoms was achieved in $86.8 \%(n=66)$ of these 76 patients. We do not routinely obtain post operative MRI scans as the cost of an MRI is more than three times that of average per capita income. Post operative scans were performed when the surgeon was concerned about the extent of tumor resection and contemplated further resection. The operative mortality was less than $1 \%$
$(0.8 \%)$ for trans-sphenoidal tumor removal at out institution, which is less than what has been previously reported. ${ }^{4,16-18}$ The incidence of major and minor morbidities in our series was comparable to what has been reported from the rest of the world. ${ }^{8}$ CSF rhinorrhea occurred in 5 patients (4\%, reported $3.9 \%)$, meningitis in 4 patients $(3.2 \%$, reported $2-6 \%)$, stroke in 1 patient $(0.8 \%$, reported $<1 \%)$ and pulmonary embolism in 2 patients $(1.6 \%$, reported $<1 \%)$. Amongst other morbidities, 14 patients $(11.2 \%$, reported $17-18 \%)$ had diabetes insipidus and 6 (4.8\%, reported up to $10 \%$ ) had other infections. Twenty two (17.6\%) patients required some form of hormone replacement beyond three months compared to the reported incidence of 3$5 \%$ of iatrogenic hypopituitarism. ${ }^{26}$ The reason for this is unclear but may have been due to aggressive attempts at tumor resection.

The sample size in our case series was neither large enough, nor truly representative of our population to permit conclusions regarding demographic differences. A few significant clues to possible demographic differences have been noticed. On the other hand, these may just be due to the economic constraints of our population and lack of available healthcare facilities which precludes international comparisons. In summary, patients in Pakistan were more likely to present either with a giant pituitary adenoma or with apoplexy. Pituitary apoplexy was found to be more common in male patients. We also found a relatively high frequency of this tumor in the pediatric population. Male patients were more likely to present with nonfunctioning adenoma and/or macroadenoma and female patients were more likely to present with functioning adenoma and/ or microadenomas. The surgical outcomes at our institution were comparable to the published literature. No statistically significant difference in outcomes was noticed between micro and macroadenomas.

\section{ACKNOWLEDGEMENT}

The authors wish to thank Professor Terence Myles (University of Calgary) for help and support during the preparation of this manuscript.

\section{REFERENCES}

1. Kovacs K, Horvath E. Tumors of the pituitary gland. Atlas of tumor pathology, fascicle 21, 2nd series. Washington, D.C, Armed Forces Institute of Pathology: 1986. p. 1-269.

2. Cardoso E, Peterson E. Pituitary apoplexy: a review. Neurosurgery. 1984;14:363-73.

3. Reinecke M, Allelio B, Saeger W, Menzel J, Winkelman W. The incidentaloma of the pituitary gland. Is neurosurgery required? JAMA. 1990;263:2772-6.

4. Laws ER, Kern EB. Complications of transsphenoidal surgery. In Laws ER, Randall RV, Kern EB, Abboud CF, editors. Management of pituitary adenomas and related lesions with emphasis of transsphenoidal microsurgery. New York, AppletonCentury-Crofts 1982; p. 329-46.

5. Dyer EH, Civit T, Visot A. Transsphenoidal surgery for pituitary adenomas in children. Neurosurgery. 1994;34:207-12.

6. Chandana A, Islam N, Jabbar A, Zuberi L, Haque N. Clinical features and outcome of surgery in 30 patients with Acromegaly. J Pak Med Assoc. 2004;54:6;315-19.

7. Chong BW, Kucharczyk W, Singer W, George S. Pituitary gland MR. A comparative study of healthy volunteers and patients with microadenomas. AJNR Am J Neuroradiol. 1994;15:4;675-9.

8. Ciric I, Ragin A, Baumgartner C, Pierce D. Complications of transsphenoidal surgery: results of a national survey, review of literature, and personal experience. Neurosurgery. 1997;40:2; 225-36. 
9. Goel E, Nadkarni T, Muzumdar D, Desai K, Phalke U, Sharma P. Giant Pituitary Tumors: A study based on Surgical Management of 118 cases. Surg Neurol. 2004;61:436-46.

10. Laws E. Surgical Management of Pituitary apoplexy. In Welch K, Caplan L, Reis D, et al, editors. Primer on Cerebrovascular Diseases. New York, Academic Press 1997:p. 221-310.

11. Hardy J. Transsphenoidal surgery of the normal and pathological pituitary. Clin Neurosurg. 1969;16:185-217.

12. Jefferson G. Extrasellar extension of pituitary adenomas. Proc R Soc Med. 1940;33:433-58.

13. Laws ER. Transsphenoidal approach to pituitary tumors. In: Shmeidek HH, Sweet WH, editors. Operative neurosurgical techniques, vol.1, Philedelphia: WB Saunders; 1995; p. 283-92.

14. Laws ER. Transsphenoidal Surgery. In Apuzzo MLJ, editor. Brain surgery: complications, avoidance and management, vol.1, New York: Churchill Livingstone; 1993;p. 357-62.

15. Thapar K, Laws ER. Pituitary tumors: Functioning and nonfunctioning. In: Winn HR, editor. Youman's Neurological Surgery. 5th Ed. Philedelphia: WB Saunders; 2004. p. 1169-206.

16. Zervas NT. Surgical results for pituitary adenomas: Results of an interventional survey. In: Black PM, Zervas NT, Ridgeway EC, Martin J, editors. Secretory tumors of the pituitary gland. New York: Raven Press; 1984;p. 377-85.

17. Semple P, Laws E. Complications in a contemporary series of patients who underwent transshpenoidal surgery for Cushing's disease. J Neurosurg. 1999;91:175-9.
18. Laws ER. Vascular complications of transsphenoidal surgery. Pituitary. 1999; 2:163-70.

19. Mindermann T, Wilson CB. Age related and gender related occurrence of pituitary adenomas. Clin Endocrinol. 1994; 41:359-64

20. Shamim SM, Hameed K. Surgically treated rectal prolapse: experience at a teaching hospital. J Pak Med Assoc. 2005;55 (6):247-50

21. Yamada S, Aiba T, Horvath E, Kovacs J. Morphological study of clinically non-secreting pituitary adenomas in patients under 40 years of age. J Neurosurg. 1991;75:902-5.

22. Annegers JF, Coulam CB, Abbound CF. Pituitary adenoma in Olmstead County, Minnesota, 1935-1977. A report of increasing incidence in women of child bearing age. Mayo Clin Proc. 1978;53:641-3.

23. Pollack IF. Brain tumors in children. N Engl J Med. 1994; 331: 1500-7.

24. Partington MD, Davis DH, Laws ER Jr, Scheithauer BW. Pituitary adenomas in children and adolescence. J Neurosurg. 1994; 80:209-16.

25. Bills D, Meyer F, Laws E, et al. A retrospective analysis of Pituitary apoplexy. Neurosurgery. 1993;33:602-9.

26. Laws ER. Pituitary surgery. Endocrinol Metab Clin North Am. 1999;28:119-31. 